\title{
Informed choice in a multicultural world
}

\author{
Mary Petrou \\ Institute of Women's Health, University College London, London, UK
}

Knowledge and autonomy are key aspects of informed choice; it is important to define what is important for participants to understand, when accepting or declining screening and for individuals to understand that screening is optional and their own personal choice

There are no agreed thresholds or minimum standards for the knowledge an individual is required to have to make an 'informed' choice. It is time that minimum agreed standards are developed for practitioners who provide genetic information.

There is no standard for evaluating good knowledge or informed choice in population reproductive genetic screening, however measuring people's choices is a good indicator of informed choice.

Informed choice in a multicultural world will be explored and an overview of the different levels of informed choice, practiced in the pathway from genetic screening to identifying at risk couples discussed.

\section{Genetic counselling and informed choice}

Genetic counselling is complex and is inseparable from medical diagnosis and aims to increase people's control of their own health and their family's health by informing them of the resources available for diagnosis and treatment and prevention. Genetic counselling is particularly important in medical genetics because of the often predictive nature of genetic information and the difficult choices people have to make.

Genetic counselling has been defined "The process by which patients or relatives at risk of a disorder that may be hereditary are advised of the consequences of the disorder, and the probability of developing and transmitting it and the ways in which this may be prevented or ameliorated" (1)

Genetic counselling requires, a correct diagnosis in the presenting family member,

explanation of the nature and prognosis of the disorder, the treatment available and where to find it, estimation of genetic risk for parents and family members. This requires drawing a family tree. It may also call for investigations on other family members. It requires communication of genetic risks and the options for avoiding them, including the chances of parents and other family members passing the disorder on to their children, and an explanation of that risk. The options for avoiding further affected children must

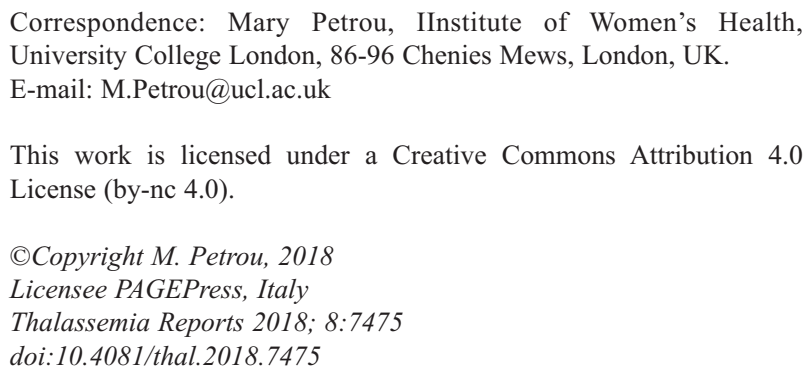

also be addressed, including techniques of prenatal diagnosis and preimplantation genetic diagnosis if it is available and associated risks including risk of error and pregnancy complications. It requires the support for the individual or couple in making the informed decision that is right for them and accessibility for longterm contact: people at risk often need counselling and support at several points in their life.

Therefore the genetic counsellor will need the skill and specialist knowledge to communicate this information, so that the individual/couple can make their informed choice. The core ethical principles of genetic counselling include; the individual/couples right to full information, the autonomy of the individual or couple and strict confidentiality (2). Information is the main therapeutic intervention in medical genetics and misinformation is the main risk. Medical training rarely equips doctors to provide adequate genetic counselling and to discuss complex issues with their patients. The responsibility involved in genetic counselling should not be underestimated. Counselling is understanding a set of facts and effectively communicating them to the individual/couple. Therefore when counselling couples who at risk for haemoglobin disorders, it is essential that non-directive counselling is used, the couples must learn the facts, think through the issues and reach a decision they can live with for the rest of their lives, there is 'no right choice'. The choice made is determined my many factors, which the counsellor must take into account, including family and reproductive history, social religious and cultural attitudes, personal experiences, economics, educational level and their understanding of their risk.

A recent lawsuit against a health care provider in Oregon highlights the importance of genetic counselling, in times where test access is becoming easily accessible. In this case a variant of unknown significance was misinterpreted by the health care providers as pathological and the woman subsequently underwent a double mastectomy and hysterectomy (3).

\section{Screening policies}

People's options are influenced by the stage in life when they are informed of their genetic risk and whether prenatal diagnosis is available. Table 1 summarises three screening policies. If the risk is identified prospectively i.e. before the birth of an affected child i.e. pre-marital, then all the available options are available to the couple, as they can choose to separate and find a non-carrier partner, they can choose to have no children, to take the chance to have children as usual and restrict family size in the hope they will not have affected children, or to use prenatal diagnosis (PND) and selective termination of affected pregnancies, if it is acceptable and available. Pre-pregnancy screening limits choices, as the choice to separate is not available and antenatal screening limits choices even further.

Unless an active screening programme is available, it is unusual for a couple to learn of their risk of having children with a haemoglobin disorder before marriage and most couples learn of their risk when an affected child is diagnosed i.e. retrospectively identified to be at risk. 


\section{Experience with screening programmes}

It is often thought that affected births can be prevented, if at risk couples are identified prior to marriage, on the assumption that they will separate and find a non-carrier partner. However in many societies, marriage is a complex phenomenon that may involve many family members besides the couple themselves and marriage partners are selected either because of a strong personal preference, or family or traditional reasons. If a planned marriage is called off it can cause social embarrassment or stigma for the young people and their families.

Before prenatal diagnosis became available marriage between carriers in Cyprus was actively discouraged, however this proved very unacceptable to the population and was soon abandoned 'because of evasions' $(4,5)$. Soon afterwards, mandatory premarital screening became available amongst the Greek Cypriots by the Greek Orthodox Church and among the Turkish Cypriots by the civil authorities. It was found that $98 \%$ of at risk- couples proceed- ed to marry and the majority used prenatal diagnosis and selective termination of affected pregnancies and consequently very few children with thalassaemia are born in Cyprus. In Cyprus, Italy and Greece the populations are well informed about thalassaemia and there has been a large fall in the birth of affected births in these Mediterranean countries (6). The outcome of the high uptake of prenatal diagnosis by couples at-risk for thalassaemia in Mediterranean countries, reflects the at risk community's view of the heavy burden of the disease and its treatment. However, things can change as treatment becomes more effective and acceptable and the uptake of prenatal diagnosis may fall if new approaches like preimplantation genetic diagnosis become easier and more widely available, then the burden of prevention may decline and uptake may rise.

Mandatory premarital screening for sickle cell and thalassaemia has been implemented in several Muslim Countries (Table 2), however it is important to discuss the acceptability of these services and the availability of the option of prenatal diagnosis and selective ter-

Table 1. Choice of screening programme.

\begin{tabular}{|c|c|c|c|}
\hline Screening policy & Options for at risk couples identified & Advantages & Limitations \\
\hline Pre-marital screening & $\begin{array}{l}\text { 1. Separation /partner choice } \\
\text { 2. Restrict family size } \\
\text { 3. PND/TOP if affected } \\
\text { 4. Neonatal diagnosis, optimal care }\end{array}$ & $\begin{array}{l}\text { Permits informed choice among } \\
\text { all available options }\end{array}$ & $\begin{array}{l}\text { 1. Limited to unmarried couples. Takes } \\
\text { over } 20 \text { years to full effect if married } \\
\text { couples not included. } \\
\text { 2. Infrastructure for premarital } \\
\text { screening may not exist. } \\
\text { 3. Uptake of service may belimited. }\end{array}$ \\
\hline Pre-pregnancy screening & $\begin{array}{l}\text { 2. Restrict family size } \\
\text { 3. PND/TOP if affected } \\
\text { 4. Neonatal diagnosis, optimal care }\end{array}$ & Targets all couples planning a pregnancy. & $\begin{array}{l}\text { 1. Infrastructure for pre-pregnancy } \\
\text { screening may not exist. } \\
\text { 2. Uptake of service may be limited. }\end{array}$ \\
\hline Antenatal screening & $\begin{array}{l}\text { 3. PND/TOP if affected } \\
\text { 4. Neonatal diagnosis, optimal care }\end{array}$ & $\begin{array}{l}\text { 1. Infrastructure (maternity services) } \\
\text { exists } \\
\text { 2. Can detect all at-risk pregnancies }\end{array}$ & $\begin{array}{l}\text { 1. Ethical only if PND with option of TOP } \\
\text { available. } \\
\text { 2. Choice limited to PND/TOP or } \\
\text { neonatal diagnosis. } \\
\text { 3. Risk often detected too late for option } \\
\text { of PND/TOP. }\end{array}$ \\
\hline
\end{tabular}

Table 2. Experience with screening programmes.

\begin{tabular}{|c|c|c|c|c|}
\hline Country/region & PND available & TOPavailable & Cancellation of marriage \% & Fall in affected births \% \\
\hline UK & Yes & Yes & & $40-50$ \\
\hline Cyprus & Yes & Yes & $<5$ & Nearly 100 \\
\hline Italy & Yes & Yes & $<5$ & Large \\
\hline Greece & Yes & Yes & $<5$ & Large \\
\hline Turkey & Yes & Yes & 13 & 90 \\
\hline Iran & Yes & Yes & $<10$ & $80-90$ \\
\hline Palestine & Yes & No & - & - \\
\hline Jordan & Yes & *No & $3-40$ & - \\
\hline Saudi Arabia & No & No & 10 & - \\
\hline Bahrain & Yes & Yes & 58 & - \\
\hline Iraqi Kurdistan & Yes & Yes & 2 & 65 \\
\hline Ras Al Khaimah, UAE & No & No & 0 & - \\
\hline India & \multicolumn{4}{|c|}{ No national programme. Some states? Premarital. Some Students } \\
\hline Pakistan & \multicolumn{4}{|c|}{ No national strategy. Regional: Punjab } \\
\hline Bangladesh & \multicolumn{4}{|l|}{ No programme } \\
\hline
\end{tabular}

*Although is available in some centres. 
mination of affected pregnancies. From a Muslim perspective, it is considered ethical to perform a termination to protect a woman's life or health, or because of a fetal abnormality incompatible with life (7). However, the stage at which termination may take place seems to vary, some Muslim jurists do not allow abortion at any stage, whilst others would permit termination in the first 120 days of fetal life, where there is a reason, such as danger to the mother or the fetus. However some jurists would only allow termination at 40 days and others at 90 days. Termination of pregnancy is absolutely prohibited after the soul is breathed into the fetus after 120 days of fetal life. Muslim theologians regard foetal development as occurring in three stages, each lasting 40 days: the sperm cell and ovum, the clump resembling a blood clot and the lump of flesh (foetus). At the end of these stages, the fetus is ensouled. However, the belief that ensoulment occurs only after120 days does not change the fact that life starts at a much earlier stage of the embryo's development. (8).

The objective of premarital screening programmes in Middle East countries where termination of pregnancy is illegal, is to reduce the prevalence of beta thalassaemia through genetic counselling and to discourage at-risk marriages,

Mandatory premarital screening was implemented in Saudi Arabia in 1994, with the objective of decreasing at-risk marriages. However' following counselling almost $90 \%$ of couples married, despite being aware of their risk and being actively discouraged from marrying. The option of prenatal diagnosis is not generally available in Saudi Arabia (9). More recent data from Saudi Arabia would suggest that the majority of at-risk couples still precede to marry following premarital screening. A cross sectional study by Sulaiman et al, looked at three groups: general population, couples presenting for premarital screening and couples who had received their premarital screening results. They found that nearly $70 \%$ of the general population felt that at-risk couples should not be allowed to marry. However they also found that $90 \%$ of couples proceeded to marry (10)

Iran, a large country in the Eastern Mediterranean region, has a comprehensive primary health care system capable of reaching every family, which incorporates regular in-service staff training. The majority of affected thalassaemia patients are diagnosed and every effort is made to provide the best possible treatment, significantly improving survival rates. As a result, the number of thalassaemic patients under treatment was increasing by about 1,200 per year with over 20,000 attending dedicated treatment centres. The costs of optimal treatment (11) was about $\$ 150$ million a year, equivalent to almost $8 \%$ of total national health expenditure. If the trend continued, future costs could rise to over half the national health expenditure. As this is obviously unfeasible, a national programme providing premarital genetic screening, genetic counselling and prenatal diagnosis was developed. Following a careful pilot study, premarital thalassaemia screening was introduced in 1997 (12). The results were considered at the highest medical and political levels, where they were understood to represent the verdict of the people, and a fatwa was issued permitting termination of pregnancy up to 120 days fetal life, when a fetus is confirmed as having a serious disorder. For reasons of cost efficiency and to reduce the possible stigma for women, many centres test the man first, only testing the woman if his result is positive. Prospective couples that are both carriers see a trained health worker, usually a doctor for counselling. The programme is conducted according to the ethical principles of autonomy, full information and confidentiality and allows informed choice.

Annual statistics on outcomes returned by district health centres to the Ministry of Health indicated in the early years of the programme, when prenatal diagnosis

was only available through a private clinic in Tehran, only 50\% of couples identified at risk proceeded to marry. However since 2000 the figure has increased steadily. The most recent figures show that in follow up of $75 \%$ of at at-risk couples, that the separation rate is less than $10 \%$ and $82-92 \%$ of couples utilize prenatal diagnosis and of those $96 \%$ of women terminate an affected pregnancy (Ashraf Samavat personal communication). This is thought to reflect the spread of the policy of non-directive counselling and knowledge of the availability of prenatal diagnosis. A national network of DNA diagnostic laboratories is available making prenatal diagnosis accessible to all within the national health system (13). The Iranian prevention programme represents a programme where a fully informed choice is possible. Consequently there has been a more than $80 \%$ fall in affected thalassaemia major births (14).

Egypt has also been offering prenatal diagnosis to at-risk couples from some centres. There is no national programme and the majority of couples are retrospectively identified. El Beshlawy et al showed that by having an in depth discussions with the parents when an affected fetus was diagnosed, following prenatal diagnosis and focussing on the religious aspects of termination of pregnancy and the religious fatwa, which permits termination of pregnancy up to 120 days of fetal life when the fetus has a severe fetal abnormality: $100 \%$ of the mothers opted to terminate their pregnancy (15).

In Pakistan where annually over 5000 children with beta thalassaemia are born (16), there is no national prevention programme. Prenatal diagnosis was first introduced in 1994 in Pakistan by Dr Suhaib Ahmed (17,18). Before initiating the service, it was considered important to seek the views of religious scholars. Two renowned religious scholars in Pakistan gave a clear verdict permitting termination of pregnancy before 120 days of fetal life, where the foetus is indicated as having a serious disorder.

The majority of couples undergoing prenatal diagnosis in Pakistan already have an affected child. Since 1994 Dr Ahmed's centre has performed over 23.000 prenatal diagnoses for thalassaemia and over $90 \%$ of women terminate affected foetuses, however there has been little impact on the birth prevalence of thalassaemia in Pakistan, as the majority of these couples already have an affected child. Recently regional premarital screening has being offered in the Punjab area in Pakistan, it will be interesting to follow the results of such a programme.

Other programmes are shown in Table 2, in most countries where premarital screening is offered, the majority of at-risk couples go ahead and marry. The fall in affected births in countries where prenatal diagnosis and selective termination is available is high (19).

The UK Sickle cell and Thalassaemia screening programme was introduced in 2000. It is based on antenatal screening (20). The programme aims to identify carrier women by 10 weeks gestation and to offer prenatal diagnosis to at- risk couples by 12 weeks gestation with the aim of carrying out prenatal diagnosis by 12 weeks 6 days. However with antenatal screening the choice for women is limited, it is either prenatal diagnosis with selective termination of an affected fetus or neonatal diagnosis. Often at risk couples are identified late, Modell et al showed very early on that the uptake of prenatal diagnosis decreased amongst the British Pakistan population, when offered in the second trimester of pregnancy (21). Recent data from the screening programme also shows that the number of women terminating affected pregnancies for both sickle cell and thalassaemia decreases with increasing gestational age (22), highlighting the importance of early detection, counselling and offer of prenatal diagnosis. Also highlighting the importance of identifying at least women before a pregnancy and offering them counselling and advice on partner testing when planning children, or as soon as a pregnancy is confirmed. 


\section{Conclusions}

Informed choice requires clear and accurate information. Informed choice is dependent on the time in life the information is provided. The multicultural world limits choices for at-risk couples. Without PND and legal termination of pregnancy premarital screening will only succeed if couples separate. Existing programmes show that marriage cancellation is low. Fully informed choice can only be achieved with the availability of PND and legal termination of pregnancy.

\section{References}

1. Harper P. In: Practical Genetic Counselling Third Edition, Editors: Wright, Butterworth \& Co, Ltd.

2. Emery AEH, Watt MS, Clack ER. 1972. Social effects of genetic counselling. Brit Med J 1972; 1:724 726. Fletcher JC, Berg K, Tranoy KE. Ethical aspects of medical genetics: a proposal for guidelines in genetic counselling, prenatal diagnosis and screening. Clin Gen. 1985; 27:199-205.

3. GenomeWeb, Oct 27, 2017.

4. Angastiniotis MA, Hadjiminas MG. Prevention of thalassaemia in Cyprus. Lancet. 1981; 1: 369370.

5. Angastiniotis MA, Kyriakidou S, Hadjiminas M. How thalassaemia was controlled in Cyprus. World Health Forum.1986; 7:291-297.

6. WHO 1993. Unpublished report WHO/HDP/TIF/HA/93.1 Joint WHO/TIF meeting on the prevention and control of haemoglobinopathies (7th meeting of the WHO Working Group on the Control of Hereditary Anaemias). Nicosia, Cyprus3-4 April 1993 (unpublished report WHO/HDP/TIF/HA/93.1.

7. Serour GI, Aboulghar MA, Mansour RT. Bioethics in medically assisted conception in the Muslim world. Journal of Assisted Reproduction and Genetics.1995; 12: 559-565.

8. Serour GI, Dickens BM. Assisted reproductive developments in the Islamic World. Int J Gynaecol Obstet. 2001; 74:187-193. Serour GI. Attitudes and cultural perspectives on infertility and its alleviation in the Middle East Area. Paper presented at the WHO Expert Group Meeting on ART, Geneva, Sept. 2001.
9. Alhamadan ARN, Almazrou YY, Alswaidi, MF, and Choudhry, AJ. Premarital Screening for thalassaemia and sickle cell disease in Saudi Arabia. Genet Med. 2007; 9:372-377.

10. Al Sulaiman A, Suliman A, Al Mishari M, Al Sawadi A, Owaidah TM. Knowledge and Attitude towards haemoglbinopathies premarital screening programme in Saudi Arabia: Population based survey. Hemoglobin, 2008, 32 (6): 531-538).

11. Karnon J, Zeuner D, Brown J, et al: "Lifetime treatment costs of beta-thalassaemia major". Clin Lab Haematol 1999 21:377-85.

12. Samavat A, and Modell B. Iranian national thalassaemia screening programme. Brit Med J. 2004; 329:1134-1137.

13. Samavat Ashraf. (2009) Genetic Epidemiology in Iran - a basis for service development. PhD thesis, University of London.

14. Dehshal HM, Namini TM, Ahmadvand A, Manshadi M, Sadeghian VS, and Abolghasemi H. Evaluation of the National Prevention Program in Iran, 2007-2009: the Accomplishments and Challenges with Reflections on the Path Ahead. Hemoglobin, 2014; 38(3): 179-187

15. El-Beshlawy A, El-Shekha A, Momtaz M, et al. Prenatal diagnosis for thalassaemia in Egypt: what changed the parents'attitude? Prenat Diagn. 2012; 32:1-6.

16. http://www.modell-almanac.net/.

17. Ahmed S, Saleem M, Modell B and Petrou M. Screening extended families for genetic haemoglobin disorders in Pakistan". N Engl J Med. 2002; 347(15):1162-1168.

18. Ahmed S, Saleem M, Sultana N, et al. Prenatal diagnosis of beta thalassaemia in Pakistan: experience in a Muslim country. Prenat Diagn. 2000; 20:378-383.

19. Saffi M, Howard N, Exploring the Effectiveness of Mandatory Premarital Screening and Genetic Counselling Programmes for $\beta$-Thalassaemia in the Middle East: A Scoping Review Public Health Genomics 2015;18:193-203 DOI: 10.1159/000430837.

20. https://www.england.nhs.uk/wp-content/uploads/2017/06/service-specification-18.pdf.

21. B Modell, R Harris, B Lane, M Khan, M Darlison, M.Petrou, J Old, M Layton, L Varnavides Informed choice in genetic screening for thalassaemia during pregnancy: audit from a national confidential inquiry BMJ 2000;320:337-341

22. https://www.gov.uk/government/uploads/system/uploads/ attachment_data/file/595609/SCT_data_report_2015-16.pdf 